\title{
APROPRIAÇÕES DOS SABERES PEDAGÓGICOS NO INÍCIO DA FORMAÇÃO: MANUAIS E PROVAS DA ESCOLA NORMAL DE SÃO PAULO (DÉCADA DE 1870)
}

\author{
Vivian Batista da Silva \\ Universidade de São Paulo, Brasil. \\ Tatiane Tanaka Perez \\ Universidade de São Paulo, Brasil.
}

\begin{abstract}
Resumo
O artigo que aqui se apresenta examina manuais e provas feitas pelos estudantes da Escola Normal de São Paulo nos anos de 1870. Isso significa perguntar quais temas, conteúdos e referências eram ensinados no início da docência e como esses saberes eram lidos, interpretados, citados, enfim, de que modo eram apropriados. Os livros e exames analisados são indícios exemplares do que se ensinava e do que se aprendia num curso ainda em consolidação. Os livros e as provas em pauta foram, em suma, produtos e produtores de uma institucionalização e formalização dos saberes do início do magistério, revestindo-se dos temas previstos para estudo na Escola Normal, dos modos como foram desenvolvidos e da maneira como foram selecionadas e mobilizadas as referências do curso.

Palavras-chaves: manuais pedagógicos, escola normal, cultura escolar.
\end{abstract}

\section{APPROPRIATION OF PEDAGOGICAL KNOWLEDGE DURING TEACHING FORMATION: GUIDEBOOKS AND TESTS OF ESCOLA NORMAL IN SÃO PAULO (IN THE 1870's)}

\begin{abstract}
The present article aims at examining manuals and tests taken by the students of Escola Normal in São Paulo during the years of 1870 . This means asking which themes, contents and references were taught in the beginning of the teaching formation? And how was such knowledge read, interpreted, quoted, and ultimately, how was it assumed? The analyzed books and tests are perfect indications of what was taught and of what was learned from a course which was still under construction. The said books and tests were, in short, products and producers of an institutionalization as well as a formalization of knowledge in the beginning of teachership. It was


coated with the expected themes to be studied at Escola Normal, with the way they were developed and with how the references of the course were selected and used as resources.

Key-words: pedagogical manuals, normal school, school culture.

\section{APROPIACIONES DE LOS SABERES PEDAGÓGICOS EN EL INICIO DE LA FORMACIÓN: MANUALES Y PRUEBAS DE LA ESCUELA NORMAL DE SÃO PAULO (DÉCADA DE 1870)}

\section{Resumen}

El artículo que aquí se presenta examina manuales y pruebas hechas por los estudiantes de la Escuela Normal de São Paulo en los años de 1870. ¿Eso significa preguntar cuáles temas, contenidos y referencias eran enseñados en el inicio de la docencia? ¿Y cómo esos saberes eran leídos, interpretados, nombrados, o sea, de que modo eran apropiados? Los libros y exámenes analizados son indicios ejemplares de aquello que se enseñaba y de lo que se aprendía en un curso todavía en consolidación. Los libros y las pruebas en pauta fueron, en suma, productos y productores de una institucionalización y formalización de los saberes del inicio del magisterio, revistiéndose de los temas previstos para estudio en la Escuela Normal, de los modos como fueron desarrollados y de la manera como fueron seleccionadas y movilizadas las referencias del curso.

Palabras-clave: manuales pedagógicos, escuela normal, cultura escolar.

\section{L'ACQUISITION DE SAVOIRS PÉDAGOGIQUES AU DÉBUT DE L'ÉDUCATION: LES MANUELS ET LES EXAMENS DE L'ÉCOLE NORMALE DE SÃO PAULO (DÉCENNIE 1870)}

\section{Résumé}

L'article présenté ici examine les manuels et tests réalisés par les étudiants de l'École Normale de São Paulo dans les années 1870. Ils permettent de se demander quels thèmes, contenus et références ont été inculqués au début de l'enseignement et comment ces connaissances ont été lues, interprétées, citées, c'est-à-dire comment elles étaient assimilées. Les livres et les tests ici analysés peuvent être considérés comme des preuves exemplaires de ce qui a été enseigné et de ce qui était appris dans un cours encore en consolidation. En résumé, les livres et les examens en question ont été non seulement les produits mais également les producteurs de l'institutionnalisation et de la formalisation des connaissances depuis le début de l'enseignement, tout en représentant les sujets prévus pour l'enseignement à l'École Normale, la façon dont ils ont été élaborés et la manière dont les références du cours ont été sélectionnées et mobilisées.

Mots-clé: manuels d'enseignement, école normale, culture de l'enseignement. 
artigo que aqui se apresenta examina manuais e provas feitas pelos estudantes da Escola Normal de São Paulo nos anos de 1870. Tais exames datados de 1875, 1876 e 1877, juntamente com os livros, são indícios exemplares do que se ensinava e do que se aprendia sobre ensino num curso ainda em consolidação. No Brasil, as escolas normais foram instituídas pelo Ato Adicional de 1834, mas durante toda a segunda metade do século 19 e início do século 20 elas tiveram uma existência instável. Nas diversas províncias do país, as escolas abriam e fechavam de acordo com decisões e interesses políticos, logrando de algum êxito a partir da década de 1870 (Tanuri, 1979; Villela, 1990, 2002; Monarcha, 1999), período que nos interessa. Os manuais e as provas em pauta foram, em suma, produtos e produtores de uma institucionalização e formalização dos saberes do início do magistério, revestindo-se dos temas previstos para estudo na escola normal, dos modos como foram desenvolvidos e da maneira como foram selecionadas e mobilizadas as referências do curso.

A ideia de apropriação é fundamental no presente trabalho, pois se considera que entre os textos das aulas e a escrita das provas há um espaço de leitura (Chartier, 1998). Ao lerem e produzirem textos, muito provavelmente os normalistas não se limitaram a uma mera reprodução do que Ihes foi ensinado durante o curso. Como todo e qualquer leitor, eles se viram diante das determinações que, de alguma forma, direcionaram as interpretações dos livros, no caso, os manuais da Escola Normal. Como diria Chartier, "os poderes ou os experts sempre querem fixar um sentido e anunciar a interpretação correta que deve impor limites à leitura (ou ao olhar). Todavia, a recepção também inventa, desloca e distorce" (1998, p. 9). É nesse sentido que se tomam suas provas como o resultado de uma série de elementos. Elas dependem das leituras propostas, das competências dos normalistas e também das expectativas de seus professores. Esses exames são produzidos a partir das regras que definem a condição e o ofício do aluno (Perrenoud, 1995), afinal, "tudo leva a crer que diversos anos de prática num tipo definido de organização arrastam consigo a formação de um conjunto de esquemas de ações, de pensamentos, de avaliação, de antecipação, daquilo que se chama, em sociologia, um habitus" (Ibid., p. 32).

Se a escola conta com regras de comportamento definidas a partir dos lugares ocupados por suas diferentes personagens, convém perguntar sobre como a Escola Normal direcionou as relações com o conhecimento e com a leitura. No intuito de saber como os normalistas se apropriaram dos saberes pedagógicos, vale atentar para os materiais ainda disponíveis, os objetos, os textos, os documentos que formaram parte do utilitário desses alunos e de seus docentes.

Ao tratar de um desafio como esse, Escolano (2011) assinala a ideia de cultura escolar numa perspectiva especialmente útil em nossa análise ${ }^{1}$. Trata-se de entender a história da Escola Normal e de uma cultura específica a ela como uma história de recepções, acomodações, recusas e resistências. Isso significa que para além das normas postas pelo currículo, do desenvolvimento dos programas e das leis que regulam o cotidiano das salas de aulas, há que se tomar em conta o que o autor denomina de cultura empírica da escola (lbid.), marcada por um amálgama de normas oficiais e de práticas informais. O exame dos manuais e das provas da Escola Normal coloca-se

\footnotetext{
${ }^{1}$ As discussões sobre cultura escolar são amplas e especialmente úteis entre os historiadores da educação, tal como as contribuições de Chervel (1990) e Julia (1995). 
justamente na interação entre o que é ensinado e o que é aprendido, ocupando um lugar específico na dinâmica de construção da cultura da Escola Normal.

Com essa finalidade, articulamos resultados de pesquisas distintas, mas aproximadas pelas questões que colocam. Um dos trabalhos tem como objeto de pesquisa o conhecimento pedagógico em curso na Escola Normal no final do século 19 (Perez, 2012). Esse conhecimento pôde ser averiguado pelas provas de final de ano dos alunos da referida escola, realizadas nos anos de 1875, 1876 e 1877, bem como por alguns manuais pedagógicos. Estes livros foram objeto da outra pesquisa aqui mobilizada, que analisou os títulos publicados no Brasil (Silva, 2001) e em Portugal (Silva, 2005). Os alunos da escola normal usaram os manuais para estudarem pela primeira vez as questões relativas ao ofício de ensinar e passaram pelos exames para mostrar o quanto tinham aprendido dessas leituras e que assim estavam aptos a exercerem a profissão. Falamos, portanto, de um material cuja natureza é variada, mas que visa a uma finalidade comum, ou seja, a de instituir os saberes a partir dos quais os normalistas conceberam sua profissão.

Ao colaborarmos com uma série de estudos já desenvolvidos sobre o funcionamento das escolas normais (Bauab, 1972; Monarcha, 1999; Tanuri, 1979; Villela, 1990, 2002;), queremos saber como os normalistas estudavam, o que liam, o que Ihes era exigido nas provas para aprovação no curso. Já fizemos essa pergunta inicialmente: de que maneira os normalistas mobilizavam seus manuais para responder às questões? Ao assinalarmos uma cultura profissional do magistério (Perrenoud, 1995) e, mais especificamente, uma cultura própria da Escola Normal, assinalamos o fato de que nesses cursos foram construídos modos de ensinar e aprender cujo funcionamento pode ser comparado a uma espécie de arquitetura na qual os programas, as leituras, as atividades e as avaliações estiveram sistematicamente relacionadas (Perrenoud, 2008).

Trata-se de uma espécie de funcionamento didático ou, como também se poderia denominar, um sistema de ensino em que todos os aspectos dependem entre si, de modo que o princípio da avaliação, por exemplo, depende do que se espera do aluno, do que se ensina e como se ensina. As aulas e as provas dependem, nessa perspectiva, das formas pelas quais os tempos e espaços de estudos são divididos. Essa abordagem sistêmica conduz a pensar que o estudo dos manuais e das provas permite conhecer diversos aspectos da vida dos normalistas, considerando suas estratégias de leitura, escrita, enfim, de sobrevivência (Perrenoud, 1995) no curso, bem como o modo pelo qual os professores identificavam e classificavam seus erros.

Para dar conta da complexidade do que se toma aqui como arquitetura do que ensinar e aprender na Escola Normal e das leituras aí produzidas, a próxima parte do artigo analisa a estruturação do ensino, tal como pode ser apreendida no estudo dos manuais pedagógicos usados pelos normalistas. Em seguida interroga-se sobre a apropriação que esses alunos fizeram dos saberes ensinados, o que significa examinar as provas feitas por eles, evidenciando como eram feitas, quais conteúdos mobilizavam, que tipo de perguntas faziam e como eram realizadas. Trata-se, em suma, de pensar sobre como foram arquitetados os saberes da docência. 


\section{A produção e circulação de saberes para os normalistas nos manuais pedagógicos}

Ao reler ou ao ler esse manual, que muito se parecia com aqueles que conheci ao tempo em que era estudante secundário, fiz a seguinte pergunta para mim mesmo: será que a literatura pode ser para nós algo que não uma lembrança de infância? Quero dizer: o que é que continua, o que é que persiste, o que é que se fala da literatura depois do colégio? (Barthes, 1988, p. 53)

As palavras de Roland Barthes referiram-se a um manual de história da literatura francesa. Amplamente difundido nas mais diversas partes do mundo, esse tipo de impresso suscitou reflexões acerca dos modos pelos quais uma determinada realidade foi dada a ler. O que foi possível lembrar da literatura estudada no colégio? correspondeu, portanto, a uma interrogação central no trecho acima transcrito e induziu a fazer, aqui, a seguinte pergunta acerca dos manuais de formação docente: o que constituiu o ensino para os professores? Importantes lições puderam ser extraídas das incursões feitas por Barthes e uma delas referiu-se ao fato de que os manuais sempre transformaram um determinado tema num objeto de ensino. Assim, se durante a vida na escola secundária foram aprendidos os principais conteúdos de disciplinas como a literatura, organizados em manuais, o mesmo ocorreu na Escola Normal, onde foram aprendidos os principais conteúdos relacionados ao ofício de ensinar, sistematizados nos livros escritos com essa finalidade.

A produção desses textos ocorreu durante a constituição de sistemas de ensino públicos, obrigatórios, gratuitos e organizados pelo Estado. Os investimentos não se dirigiram, nessa perspectiva, à formação de um único discípulo, mas ampliaram-se para o povo e, por isso, os manuais pedagógicos vincularam-se aos projetos de expansão da escola. Esses títulos foram usados desde o século 19 nas mais diversas partes do mundo: em Portugal, no Brasil (Silva, 2005) e em outros países, como a França (Roullet, 1998) e a Espanha (Fernández e Salvado, 1998; Pintado, 2000), onde houve esforços para ampliar as oportunidades escolares. Tais impressos foram leitura obrigatória, sobretudo entre aquelas pessoas que não tiveram acesso a graus mais elevados de instrução (Nóvoa, 1987) e que, para ingressarem na carreira docente, limitaram seus estudos ao âmbito das escolas normais ou do preparo para concurso de admissão na carreira do magistério.

Se os manuais foram feitos para formarem um grande e crescente número de professores, podemos tomá-los como produtos da escola feita para o povo. Além de produtos desse modelo de ensino, eles foram ao mesmo tempo um dos produtores dos modos de funcionamento da escola, já que explicaram a composição dos elementos da vida nessa instituição, ou seja, as atribuições do docente, as atividades do aluno, o funcionamento das aulas, a organização dos conteúdos, os métodos didáticos.

Ao se afirmar que os manuais pedagógicos tiveram o ensino como seu objeto de ensino, o intuito foi remeter para as relações desses livros com a formação dos professores feita no interior dos projetos de democratização das oportunidades escolares. Os manuais fizeram circular saberes sobre o ofício de ensinar, tomando-os como temas a serem explicados durante as aulas na Escola Normal. Eles manifestaram rituais das aulas a serem ministradas pelos normalistas quando explicaram determinadas idéias e

\begin{tabular}{|l|l|l|l|l|l|}
\hline Hist. Educ. [online] & Porto Alegre & v. 18 & n. 42 & Jan./abr. 2014 & p. 93-113
\end{tabular}


sugeriram procedimentos e atividades a serem reproduzidos futuramente pelos estudantes no exercício do magistério. Assim, esses textos definiram regras ideais para se conduzir o ensino ou, em outras palavras, delimitaram rituais ou ritos específicos da escola primária. Além de produzirem assim elementos de uma cultura escolar (Chervel, 1990; Julia, 1995), os livros dos normalistas foram lugares de uma cultura pedagógica (Escolano, 2002) porque essas orientações acerca da organização do ensino primário foram o núcleo das preocupações com a própria formação do magistério e, portanto, de uma cultura específica dos professores. Um propósito sempre foi notável nos manuais pedagógicos: formar os futuros professores, garantindo-lhes um primeiro contato com os saberes pedagógicos, de uma forma acessível e facilitada.

Os primeiros manuais pedagógicos foram publicados quando o Estado passou a regular o ingresso na carreira do magistério, seja pelos concursos, seja pelas escolas de formação (Silva, 2005). E essa foi uma tendência notável não apenas no caso brasileiro, como também em países como a França (Roullet, 2001) e Portugal (Silva, 2005). Na década de 1870, período que nos interessa aqui por marcar a consolidação das escolas normais, um dos manuais mais utilizados no Brasil e, especialmente, na Escola Normal de São Paulo foi uma tradução do Curso prático de pedagogia, destinado aos alunosmestres das escolas normais primárias e aos instituidores em exercício, de mr. Daligault, publicado originalmente na França em 1851. Lourenço Filho constatou que a obra foi editada pela primeira vez no Brasil em 1865: "A primeira obra de doutrina sistemática data de 1865, numa tradução do Compêndio prático de pedagogia, de Daligault, devida a Joaquim Pires Machado Portela, que imprimiu, nesse ano, a primeira edição no Recife, vindo a dar, logo após, a segunda, no Rio" (1941, p. 30).

As relações entre os manuais pedagógicos e as orientações dos cursos de formação para o magistério deixaram entrever um elemento determinante dos conteúdos desses livros, ou seja, a estreita dependência com os programas das disciplinas de Pedagogia, Didática, Metodologia e Prática de Ensino. Por isso, foi possível articular os livros da Escola Normal ao chamado currículo editado (Escolano, 2002), tomando esses textos como a vulgata de determinadas disciplinas e dos modos pelos quais elas se constituíram no decorrer dos anos (Chervel, 1990).

Os autores dos livros reconheceram o caráter não original e até menor de seus textos. Esses escritores conheceram a grande literatura pedagógica e assumiram o compromisso, aparentemente simples, de apresentá-la de modo rápido e acessível, mas não original. Ao assumirem sua posição inferior em relação à chamada alta Pedagogia ${ }^{2}$, esses escritores acabaram por revelar sua cultura enciclopédica e justificaram porque tinham, afinal, legitimidade para resumir e ensinar o que houve de melhor na bibliografia sobre educação, intermediando a leitura que os professores fizeram dos grandes pensadores da área educacional.

Os manuais pedagógicos ocuparam esse lugar intermediário no campo da educação. Ou seja, eles foram produções dos educadores que apresentaram os grandes teóricos e pedagogos aos professores. Os seus textos explicaram as questões de ensino de forma concisa, dando pouco espaço para a descrição de discussões entre os

\footnotetext{
${ }^{2}$ A distinção entre alta e baixa pedagogia foi feita por Depaepe $(2000 ; 2002)$ para delimitar as características de um discurso de tipo pragmático e mais próximo da chamada baixa pedagogia e outra modalidade mais científica e próxima da alta pedagogia. 
educadores. As revistas educacionais, por sua vez, puderam ocupar múltiplas posições (Catani, 1994) e, dependendo de sua natureza, os periódicos estiveram mais abertos ao debate e à polêmica (Rogan e Luckowski, 1990), evidenciando proximidades ou tensões com associações estudantis, com o Estado e com as diferentes áreas de saber. O mesmo não ocorreu com os manuais pedagógicos. Isso não quer dizer que a posição desses livros tenha sido estática, pelo contrário, o seu conteúdo dependeu de uma rede de comunicação complexa e decorreu de opções e leituras historicamente situadas.

Ao cumprirem o seu papel de mediadores de uma gramática recontextualizada (Bernstein, 1986), os manuais pedagógicos acabaram por apresentar relações muito específicas: afirmaram-se enquanto sínteses apenas, obras nada originais, apenas resumos, retomadas de outras idéias. Daí chamá-los aqui, com base nas considerações de Bourdieu (1996) acerca da produção de leituras em determinados espaços, textos de leitores. Poderíamos ser induzidos a usar a metáfora ladrões de palavras (Schneider, 1990), chamá-los de obras menores ou do grupo da baixa Pedagogia (Depaepe, 2000, 2002), já que responderam a uma necessidade muito pontual, a do desenvolvimento de cursos profissionalizantes para futuros professores e, por conta disso, na maior parte das vezes restringiram o seu conteúdo a uma espécie de receituário de como exercer o magistério. Poucas vezes eles foram referidos em revistas educacionais, quase nunca foram objeto de resenhas feitas por educadores. Eles tenderam a serem esquecidos por quem os usou na Escola Normal, daí a dificuldade, inclusive, de proceder ao levantamento dessa fonte. Além disso, esses livros não se preocuparam em dar luz a polêmicas do campo educacional, pelo contrário, até quando situaram esse tipo de questão, usaram um tom mais expositivo e objetivo, de quem não tomou partido.

Poderíamos, então, discutir com mais apuro o que implicou a natureza do manual, pois, no lugar do que se costumou analisar apenas como um trabalho menor de compilação, foi possível assinalar um trabalho de seleção e eleição do que houve de melhor na área educacional. Os manuais se separaram, de certa forma, dos outros impressos que constituíram a imprensa de ensino. Assim os manuais indicaram sua condição menor, excluindo-se, em certa medida, da bibliografia consagrada da área, porque assim puderam marcar suas especificidades e traduziram alguns conhecimentos para os professores na fase inicial de formação. No decorrer de praticamente um século de publicação, os manuais oscilaram entre o que Depaepe $(2000,2002)$ chamou de alta e baixa pedagogia, porque as suas configurações foram historicamente situadas (Silva, 2005). Isso se deveu à própria natureza desses livros, que se transformaram em função da organização do ensino normal. As características dos manuais e as várias iniciativas a partir das quais eles foram produzidos foram, portanto, aspectos essenciais para compreender a historicidade desses textos e os modos pelos quais eles contribuíram com a formação inicial dos professores primários (Silva, 2005).

\section{As apropriações dos saberes pedagógicos nas provas da Escola Normal}

As primeiras iniciativas de formação institucional de professores foram decorrência da expansão da escola, ocorrida ao longo do século 19, não apenas no Brasil, mas também na Europa. A partir do Ato Adicional de 1834 a escola normal brasileira começou a ser criada em algumas províncias, já que a reforma deixou a cargo das mesmas legislarem sobre a instrução pública e seus estabelecimentos, exceto no que se referiu às 
escolas de ensino superior, que continuavam a cargo do governo central. Nesse cenário, foi criada a primeira Escola Normal da Província de São Paulo, aberta em 1846 e fechada pela primeira vez em 1867. Postulou-se, sobretudo a partir da década de 1870, a formação profissional dos professores por um ensino institucionalizado, com a leitura de livros, estudo dos métodos de ensino e exercícios práticos. Em 1875, a escola foi reaberta e, ao final desse mesmo ano, foram realizados os primeiros exames da Escola Normal de São Paulo, prática que se repetiu nos anos subsequentes.

A partir desse ano, os exames para provimento dos cargos de professor de instrução pública primária passaram a ser realizados pela Escola Normal, sob os mesmos critérios e conteúdos das provas a que eram submetidos os alunos do curso. O referido exame deveria ser realizado pelos candidatos ao cargo de professor público que não tivessem realizado o Curso Normal, substituindo o certificado de habilitação recebido pelos normalistas. Tais exames eram muito criticados pelos defensores da escola normal. Eles eram conhecidos como exames vagos e extraordinários e só foram suprimidos com a aprovação do Regulamento da Escola Normal, de 22 de agosto de 1887. Quanto aos professores públicos em exercício que não tivessem o certificado de normalista, poderiam matricular-se naquela escola, recebendo seus ordenados pelo período de dois anos, tempo de duração do curso. Em 1876 a lei n. 55 estabeleceu a abertura da seção feminina do curso normal, que passou a funcionar em horário diverso da seção masculina, cujas aulas eram ministradas pelos mesmos professores. Em 1878 a escola foi novamente fechada.

Uma importante fonte de identificação do conhecimento pedagógico em curso na Escola Normal de São Paulo, no final do século 19, foram as provas de final de ano dos alunos normalistas, exames datados de 1875, 1876 e 1877 (Perez, 2012). Esse conjunto documental, com 73 provas analisadas, eram dissertações cujos pontos eram definidos pelos examinadores, professores da Escola Normal. Eles preparavam uma lista da qual apenas um ponto era sorteado no dia da prova. Tais exames eram publicados em edital pela Inspetoria Geral da Instrução Pública, registrados em livro ata e realizados na presença de autoridades, que também compunham a banca examinadora. Dentre a documentação localizada foi possível identificar os alunos presentes nos diversos dias dos exames realizados no ano de 1875, informações sobre data e local em que foram realizados os exames, responsáveis presentes, no caso o inspetor geral e diretor da Escola Normal e os dois professores da escola, justificativas de ausência de professores e alunos aos exames, horário de início e término das provas, horário em que cada aluno avaliado entregou seu exame, tema da prova etc.

De forma geral esses exames continham no cabeçalho o tema sorteado, na sequência a dissertação do aluno sobre o tema proposto e, logo abaixo do texto, constavam a data e o nome completo do examinado. Nas marcas de correção dos examinadores constavam o conceito e a assinatura de dois examinadores, professores da escola, às vezes mencionando a data da correção. Os conceitos utilizados na avaliação variavam entre muito boa, boa, sofrível e má.

Conforme assinalado anteriormente, em sua maioria, esses exames eram feitos pelos normalistas, mas também por aqueles que pleiteavam uma vaga como professor de instrução pública primária e que não possuíam o certificado de normalista. Tais exames representam um importante suporte material dos discursos educacionais presentes na 
formação do futuro professor, seja por expressarem a opinião daqueles que a realizam, seja por trazerem indícios acerca dos conteúdos ensinados, na proposição dos pontos de avaliação e, inclusive, com a citação de autores de manuais pedagógicos pelos normalistas, ou ainda por contribuírem para a compreensão da construção de uma identidade profissional e formação docente, na medida em que trazem expressas prescrições acerca da postura adequada enquanto professor, do que e do como ensinar (Perez, 2012).

Por meio dessas provas, ancorado nas prescrições existentes nos manuais de formação de professores, parece possível identificar algumas das normas e das finalidades que deveriam reger a escola que se pretendia instaurar, objetiva ou subjetivamente. Ademais, identificou-se também o papel que se esperava que o professor desempenhasse nessa instituição, bem como algumas práticas escolares e conteúdos gerais entendidos como necessários para formar os futuros cidadãos (Perez, 2012).

Logo que foi reaberta a Escola Normal de São Paulo, no ano de 1875, o livro base para o ensino de Pedagogia era o Curso prático de pedagogia, de mr. Daligault. Como foi possível depreender do exame das provas da Escola Normal, a obra de Daligault (1874) foi o livro usado nas aulas de Pedagogia e seus escritos é que foram mobilizados pelos alunos em suas avaliações. A citação do nome do autor em inúmeros exames, somada a uma análise mais atenta de seus conteúdos, permite perceber trechos idênticos ao do referido manual, transcritos pelos alunos. Ademais, os pontos para os exames dos alunos dos anos de 1875, 1876 e 1877 reproduziram os temas abordados na obra e, às vezes, os mesmos títulos encontrados no índice do livro, tal como demonstrou Trevisan (2011). Seria possível, então, considerar o Curso prático de pedagogia, de Daligault, como uma espécie de fundador dos discursos que fundamentam as representações da docência no período, já que suas ideias circularam e foram apropriadas pelos futuros professores (Perez, 2012).

Nos exames da Escola Normal as palavras de Daligault foram transcritas muitas vezes, o que não significou uma mera cópia ou memorização, mas sim o reconhecimento, por parte dos futuros professores, do quanto elas eram valorizadas para legitimar o exercício do magistério. Conhecer Daligault significou, em última instância, dominar um tipo de capital que dava a licença para ensinar. As transcrições, paráfrases e menções de trechos de Daligault podem ser interpretadas como uma estratégia para obtenção do diploma. Memorizar e transcrever a ideia do autor solicitado na prova da forma mais fiel possível foi, aliás, uma prática comum entre os alunos. Não só na Escola Normal como também nas mais variadas classes e níveis de ensino, aprende-se a escrever o que o professor quer que se escreva, garantindo-se assim a obtenção da nota que, em última instância, é a condição para ser aprovado. Conseguir boa nota é uma das principais atribuições do ofício de aluno (Perrenoud, 1995) e, como vimos, os alunos-normalistas, que também eram futuros professores, continuavam usando essa estratégia na Escola Normal. 
Figura 1

Pontos para os exames de Pedagogia - 1875, 1876, 1877.

\begin{tabular}{|c|c|c|}
\hline \multicolumn{3}{|c|}{ Pontos para as provas de Pedagogia da Escola Normal de São Paulo } \\
\hline \multirow{12}{*}{1875} & \multirow{12}{*}{ 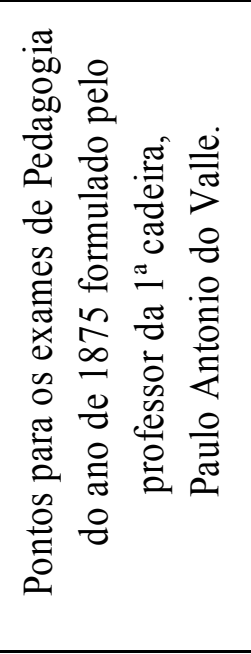 } & $\begin{array}{l}1^{\circ} . \text { O que seja Pedagogia, qual sua matéria, e em quantas partes se } \\
\text { divide o seu estudo }\end{array}$ \\
\hline & & $2^{\circ}$. Educação e Instrução \\
\hline & & $3^{\circ}$. Espécies de educação \\
\hline & & $4^{\circ}$. Educação física \\
\hline & & $5^{\circ}$. Educação intelectual \\
\hline & & $6^{\circ}$. O professor e seus predicados \\
\hline & & $7^{\circ}$. A escola e suas condições materiais \\
\hline & & $8^{\circ}$. Mobília e utensílios da Escola \\
\hline & & $9^{\circ}$. Métodos de ensino \\
\hline & & $10^{\circ}$. Penas e recompensas na Escola \\
\hline & & $11^{\circ}$. Meios disciplinares da Escola \\
\hline & & $11^{\circ}$. Métodos de leitura $*$ \\
\hline \multirow{12}{*}{1876} & \multirow{12}{*}{ 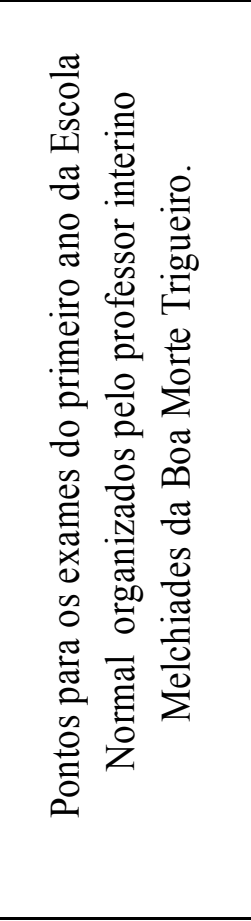 } & $\begin{array}{l}1^{\mathrm{o}} \text {. - Preliminares. Dignidade das funções do professor. Qualidades } \\
\text { que se referem direta e indiretamente às suas funções }\end{array}$ \\
\hline & & $\begin{array}{l}2^{o} . \text { - Definição, objeto e divisão da pedagogia. Definição e divisão da } \\
\text { educação. Distinção entre educação e instrução em acepção } \\
\text { pedagógica. }\end{array}$ \\
\hline & & $\begin{array}{l}3^{\text {o }} \text { - Educação física. Meios indiretos e diretos. Educação dos órgãos } \\
\text { dos sentidos. }\end{array}$ \\
\hline & & $\begin{array}{l}4^{\circ} . \text { - Educação intelectual. Distinção entre educação intelectual e } \\
\text { instrução propriamente dita. }\end{array}$ \\
\hline & & $5^{\circ}$. - Educação Moral e religiosa. \\
\hline & & $\begin{array}{l}6^{\circ} .- \text { Métodos de ensino individual e simultâneo; seus inconvenientes e } \\
\text { vantagens. }\end{array}$ \\
\hline & & $7^{\circ}$. - Métodos de ensino mútuo e misto; suas vantagens e defeitos. \\
\hline & & $8^{\circ} .-$ Métodos de leitura. \\
\hline & & $9^{\circ}$. - Métodos de escrita. \\
\hline & & $10^{\circ} .-$ Métodos de aritmética. \\
\hline & & $11^{\circ}$. - Instrução moral e religiosa. \\
\hline & & $12^{\circ}$. - Arranjo e direção da aula. \\
\hline \multirow{9}{*}{1877} & \multirow{9}{*}{ 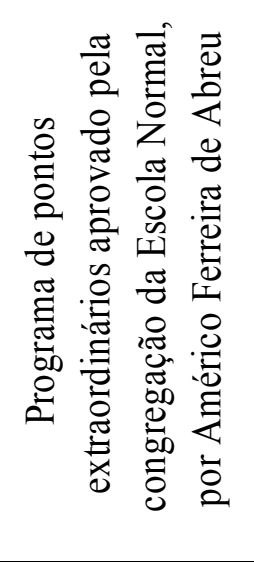 } & $1^{\circ}$. Ano - Pontos para prova e s crita \\
\hline & & $\begin{array}{l}1^{\circ} \text {. Qualidades que se referem direta e indiretamente às funções do } \\
\text { professor. }\end{array}$ \\
\hline & & $2^{\circ}$. Distinção entre educação e instrução. \\
\hline & & Pontos para prova oral \\
\hline & & $1^{\circ}$. Educação intelectual. \\
\hline & & $2^{\circ}$. Educação moral e religiosa. \\
\hline & & $\begin{array}{l}3^{\circ} \text {. Métodos de ensino individual e simultâneo, suas vantagens e } \\
\text { inconveniências. }\end{array}$ \\
\hline & & $4^{\circ}$. Método de ensino mútuo e misto, suas vantagens e defeitos. \\
\hline & & $5^{\circ}$. Instrução Moral e religiosa. \\
\hline
\end{tabular}

Fonte: Perez, 2012, p. 93. 
Além da bibliografia usada nos exames, podemos inferir aspectos importantes do quadro de pontos sugeridos para a elaboração dessas provas. Ao identificarmos esses pontos, notamos que os temas comuns exigidos nos três primeiros anos da primeira reabertura da Escola Normal concentraram-se em três eixos:

1) os diferentes tipos de educação: a intelectual, a física, a moral e a religiosa;

2) os métodos de ensino, gerais ou específicos;

3) as qualidades necessárias ao exercício da profissão, ou seja, as representações de um ideal de professor (Perez, 2012).

Se queremos entender como os saberes pedagógicos foram construídos e apropriados na Escola Normal, convém atentar para os temas das provas finais. Eles foram indícios do que se considerou ser essencial ao exercício da profissão docente no final do século 19. A seguir, nos deteremos numa breve análise de cada um desses eixos que articularam os conteúdos dos exames e regularam os conhecimentos exigidos dos futuros professores.

\section{A educação integral: formando cidadãos instruídos e dóceis}

Nas perguntas feitas aos normalistas, as provas de Pedagogia deixaram entrever a preocupação da disciplina em assinalar as finalidades da educação e da escola. Foram essas finalidades que justificaram os investimentos na edificação dos sistemas nacionais de ensino desde a metade do século 19 nas mais diversas partes do mundo (Nóvoa; Schriewer, 2000). As escolas normais assumiram um papel decisivo no desenvolvimento desses projetos, já que se responsabilizaram pela difusão dos saberes que fundamentaram o trabalho dos professores. No Brasil foi notável um movimento semelhante. Como assinalou Leonor Tanuri (2000), a criação das escolas destinadas ao preparo para o magistério também se vinculou à institucionalização da instrução pública, inspirada nas idéias liberais de secularização e extensão do ensino primário.

Entre os pontos que deveriam ser conhecidos entre os normalistas para obtenção do diploma de professor primário, o tema da instrução teve lugar de destaque. De acordo com a leitura dos pontos e das questões relacionadas a ele, podemos sintetizar algumas das ideias desenvolvidas na Escola Normal. Nesse contexto, a escolarização da educação trouxe consigo a necessidade de diretrizes para a organização e a prática do ensino. A formação do futuro cidadão deveria acontecer por uma educação integral, uma vez que o homem é entendido nessa perspectiva. Desse modo, o professor deveria cuidar de desenvolver as diferentes faculdades constitutivas do homem, a saber, as físicas, as morais e as intelectuais. O aluno normalista Marcellino Carvalho, por exemplo, no exame realizado em 1875, apresentou as três espécies de educação como o resultado da existência das diferentes faculdades humanas.

O estudante descreveu que à educação intelectual cabia a finalidade de desenvolver a inteligência da pessoa, de modo que ela pudesse receber os conhecimentos de que necessitava; à educação moral ou religiosa cabia a finalidade de "despertar no coração do homem todos os sentimentos da religião, isto é, os sentimentos de amor de Deus e do próximo" (prova de Marcellino Carvalho, 1875); já à educação física cabia a tarefa de "desenvolver as forças da pessoa, e torná-la, portanto, apta para os misteres da vida laboriosa". Outro aluno, Manoel Villaça (1876) destacou em sua prova a importância desse último ramo da educação, especialmente para as crianças pobres, "pois que estes 
porque são pobres, para ganhar o que lhes é necessário para alimentar-se, hão de trabalhar. O professor deverá pois esforçar-se para ter bom êxito nesta educação" (prova de Manoel Villaça, 1876).

No contexto da educação física, a postura dos meninos também foi algo ao qual o professor deveria atentar, evitando que os alunos tomassem má posição, como se afirmou nas provas. Elas ainda assinalavam que tais cuidados deveriam zelar pela integridade do desenvolvimento muscular dos meninos e pela ordem e disciplina da aula. Como apontou o normalista Antonio Dias em seu exame de 1876: "Importa muito não só ao desenvolvimento físico do menino como a boa ordem que deve reinar na aula, que eles [alunos] tenham conveniente posição" (prova de Antonio Dias, 1876). Tamanha atenção destinada aos cuidados físicos apontou para diferentes aspectos: sobre a necessidade de se educar os corpos dos alunos para o cumprimento da tarefa educativa, tornando-os obedientes e dóceis (Foucault, 1987), consequentemente, sobre a conveniência de exercitá-los tornando-os aptos aos "misteres da vida laboriosa" (prova de Antonio Dias, 1876; e outros), ou seja, preparando-os para o trabalho. Podemos ainda inferir, pelos indícios trazidos pelas abordagens feitas, parte do discurso médico disseminado, que pretendia modelar e higienizar os corpos com o intuito de construir uma sociedade higienizada com o auxílio da organização escolar (Gondra, 2000).

Outro indício do projeto civilizador que se pretendia no período em estudo pode ser identificado na ideia disseminada de educação intelectual e de instrução propriamente dita. A distinção entre elas foi tema de cinco dentre as 73 provas analisadas. $O$ aluno Pedro Amaral (1875) apresentou tal distinção de maneira bastante elucidativa das intenções em pauta. Em suas palavras, "a educação recai sobre a moral e a instrução supõe outros princípios mais elevados, ideias mais extensas, regras metódicas, que servem para ilustrar a razão, adornar o entendimento, aperfeiçoar o coração e suavizar os costumes" (prova de Pedro Amaral, 1875). Em outras passagens das provas parece evidente a intenção de inculcar no futuro professor a tarefa da educação escolar enquanto responsável pela formação do cidadão de maneira integral, ou seja, aquele que deveria servir à Pátria, ser fiel à religião e filho trabalhador.

Nesse contexto, a racionalização e controle dos processos e práticas escolares foram resultado da intenção de se fazer da escola parte de um projeto educativo que visava ao controle e a uma dada conformação social. Desse modo, os normalistas assinalaram em suas provas a ideia de que, tendo o professor como seu principal agente, a educação escolar assumia papel relevante na formação de hábitos e práticas que se pretendia difundir entre a população. Muito provavelmente isso foi ensinado nas aulas e nos manuais pedagógicos. Como os exames deixam entrever, não houve questionamentos, especulações ou dúvidas quanto a esses propósitos. Tudo leva a crer que os alunos foram fortemente guiados pelo professor e a unanimidade das respostas nos conduz a perguntar aqui se isso não foi mais uma estratégia dos normalistas para obter nota do que uma mera cópia daquilo que foi ensinado nas aulas (Perrenoud, 1995). 


\section{Os métodos de ensino e a organização escolar}

Outra vertente notória de estudos na Escola Normal do final do século 19 correspondeu aos métodos de ensino ${ }^{3}$. A leitura dos pontos e das questões postas aos alunos evidencia que, após o tratamento da necessidade de expansão da escolarização à população, os métodos de ensino seguiram como o tema de destaque na formação docente. A aluna normalista Olympia Mendonça, em prova feita no ano de 1877, definiu método como "os meios que se servem os mestres para facilitar o progresso dos alunos", possuindo esse método duas divisões: "Método geral é aquele que preside a própria organização da escola; método particular é aquele que se emprega no ensino de cada matéria" (prova de Olympia Mendonça, 1877). Essa ideia também foi apresentada no manual de Daligault (1874) que, evidentemente, foi a fonte consultada por essa aluna e outros normalistas que realizaram o mesmo exame.

Para compreender as respostas das provas, convém retomar o conteúdo dos manuais usados nas escolas. No período em estudo, os manuais pedagógicos apresentavam, em geral, quatro diferentes maneiras de organizar a escola, permitir seu bom funcionamento e garantir êxito no ensino aos alunos: individual, simultâneo, mútuo e misto. Tal como se explicou nos manuais e como apareceu nas provas da Escola Normal, o primeiro método apresentou a vantagem de permitir ao professor contato direto com seu aluno, já que o mesmo ensinaria um estudante por vez. Entretanto, o inconveniente estaria na dificuldade de se ensinar a muitos meninos - necessidade existente com a expansão da escola -, por isso, a normalista Henriqueta Faro, em prova realizada no ano de 1877, destacou: "Se adotássemos esse método numa escola, muito nos custaria cumprir nosso dever" (prova de Henriqueta Faro, 1877). Como alternativa a esse modo preceptoral, surge o método simultâneo, tido como um dos mais vantajosos, apresentando como inconveniente a aplicação a um número limitado de alunos, até 50 . Nesse método os alunos foram agrupados de acordo com o nível de conhecimento para a realização de uma mesma atividade simultaneamente.

O método mútuo foi apresentado como opção para minimizar os inconvenientes gerados pelo aumento no número de alunos atendidos. No método simultâneo o professor tratava cada classe da mesma maneira como tratava cada aluno no método individual, ou seja, cuidava de conduzir o ensino em cada uma das classes utilizando-se, porém, das mesmas tarefas a todos os alunos. No método mútuo, o professor tinha na sala dos mais adiantados seus monitores. Estes, por sua vez, eram preparados pelo professor para desempenhar sua função perante a classe dos alunos menos adiantados, cabendo ao professor apenas a inspeção geral. Nesse caso, os únicos a receberem lições diretas do professor eram os monitores, para que pudessem ser preparados para conduzir as lições nas classes inferiores.

O método misto, apresentado como opção aos inconvenientes dos métodos precedentes, era aquele que dispunha os alunos divididos em classes, da mesma forma como nos métodos simultâneo e mútuo, porém os monitores ou inspetores ficavam responsáveis pela disciplina, e o professor, pela instrução geral. Esse método se assemelhava mais ao método simultâneo, porém, ao invés de ficarem os outros alunos

\footnotetext{
${ }^{3}$ Alguns dos manuais analisados utilizam o termo modos para designar essa organização da escola (a maneira de agrupar os alunos para o ensino). Para uma informação mais detalhada, consultar Perez (2012). 
sem a supervisão do professor, enquanto este se ocupava de uma classe, estavam sob supervisão dos monitores que se incumbiam de manter a disciplina. Essas eram as descrições expostas nas provas e nos livros da Escola Normal, especialmente no de Daligault.

As metodologias descritas nos manuais pedagógicos da época e retomadas pelos normalistas em seus exames caracterizavam formas típicas do trabalho na escola moderna (Gallego, 2008). Trata-se, em última instância, de aprender a organizar as "aprendizagens em larga escala segundo uma lógica burocrática, com programas, horários, idades, métodos, critérios estandardizados" (Perrenoud, 1995, p. 83). Os normalistas aprendiam a ensinar numa organização da qual eles já participavam como alunos. Eles deveriam dominar as regras para ensinar um habitus que eles já conheciam e viviam: "Na escola, sem se saber, aprende-se a viver numa organização, que se constrói através da aprendizagem do ofício do aluno" (Ibid., p. 83). Na Escola Normal, por sua vez, aprendia-se a ensinar a viver nessa organização e os estudantes projetavam seu trabalho futuro, de professores. Enquanto pontos exigidos nos exames, os métodos pedagógicos marcavam os sentidos do trabalho na escola primária.

Carlota Boto (1997), ao analisar o contexto português, demonstra que a institucionalização do modo simultâneo de ensino, pela organização da sala, a disposição do mobiliário, do professor e dos alunos e, principalmente, pelo uso dos discípulos vigias ou monitores, ou seja, por meio da organização interna da escola, contribuiria para "um minucioso processo de fabricação da disciplina, mediante práticas de ininterrupta coerção e vigilância" (p. 106). Desse modo, evidencia-se outro aspecto presente no modo de se conduzir o ensino, no final do século 19: ele era responsável não apenas pelo êxito da ação docente no sentido de instruir a população, mas, principalmente, no sentido de estabelecer "relações de interação entre utilidade e docilidade, distribuindo de maneira privilegiada os indivíduos no espaço e buscando atribuir-lhes nova relação com o tempo". Buscava-se a uniformização, pois "a escolarização só se transformaria em efetiva demanda das populações no momento em que se houvesse de fato atingido esse ideal de uniformidade" (Ibid., p. 106). Uniformizar as práticas escolares significava, em alguma medida, disciplinar os novos cidadãos e civilizar as práticas sociais dentro dos moldes pretendidos, como podemos constatar no contexto brasileiro também.

\section{Aprendendo a ser professor}

Para a realização do projeto civilizador da sociedade pela educação, a figura do professor é essencial. Mas que perfil de professor se pretendia formar no final do século 19? Em geral, os manuais da década de 1870 e início da década de 1880 trouxeram uma seção destinada às qualidades necessárias ao exercício do magistério (Silva, 2005; Perez, 2012). A imagem do professor que se esperava formar pode ser identificada, direta ou indiretamente, tanto nos manuais, quanto nas provas dos normalistas. Esse material destacou os temas estudados na época, fundamentou-se em determinadas referências e criou representações do magistério notáveis desde o século 19. Essas representações, produzidas por discursos pedagógicos de natureza prescritiva, moralizadora, disciplinador, contidos nos livros-textos, constituem um código disciplinar que normatiza saberes e práticas interiorizando um habitus profissional, que expressa continuidades e regularidades (Bastos, 2011). 
No conjunto documental deste trabalho podemos identificar inúmeras referências ao papel do professor, suas responsabilidades no exercício da função e características que deveria possuir. A análise das provas da Escola Normal evidenciou como os alunos sentiam-se mais à vontade para escrever sobre esse tema. Vale lembrar que essas provas eram dissertativas e os pontos eram definidos pelo professor ou pelo responsável pela aplicação do exame. Encontramos um conjunto de oito provas intituladas $O$ professor e seus predicados. As provas feitas sobre esse tema das quais se tem conhecimento foram realizadas em 1875 e abordaram diretamente a questão das qualidades necessárias ao exercício do magistério.

Sobre elas, mr. Daligault trouxe uma lista detalhada e extensa, que dizia respeito a valores e atitudes que o futuro professor deveria ter, algumas delas associadas à submissão e à obediência, outras à religiosidade e ao retiro. Outros seis exames pautavam-se pelo tema da importância do professor em relação aos demais funcionários públicos. Essas provas apresentavam um discurso sobre a responsabilidade do mestre pelo futuro da nação, como eles mesmos afirmavam. Os normalistas ressaltavam, então, os argumentos de valorização da docência, enfatizada pela sua nobreza e responsabilidades frente ao progresso e êxito da Pátria. Mas esse discurso não se vinculou apenas aos objetivos de formação do cidadão, articulando também os fundamentos religiosos do magistério.

Os discursos registrados nos exames realizados na Escola Normal reforçaram um discurso presente em toda literatura educacional da época (Silva, 2005). Na legislação, em livros, manuais ou revistas especializadas da época podemos notar, de uma forma ou de outra, o quão forte foi o discurso religioso na construção de um modelo de professor no final do século 19 brasileiro. A ideia de que a docência se aproximou do sacerdócio foi enfatizada nas provas dos normalistas e, para ilustrar o tipo de argumentação desenvolvida por esses alunos, segue a transcrição de um trecho de prova escrita em 1875 por José Salgado:

O magistério primário é o verdadeiro sacerdócio. O padre zela pelo interesse espiritual, guiando, como um bom pastor, suas ovelhas pelo caminho da verdade, evita, a cada passo que elas se desencaminhem e se abismem no erro, na impiedade e na descrença. O professor, por seu turno, encarrega-se de dirigir os primeiros passos da infância, educando cuidadosamente seus alunos, corrigindo, repreendendo seus delitos, e exortando-os com bons exemplos para que sejam ou venham a ser, um dia, homens de bem; dá-lhes os primeiros princípios de moral e ensinaIhes a distinguir o bem do mal. (Prova realizada por José Salgado no ano de 1875)

Fica evidente, pela análise das provas, a expectativa de que o professor fosse uma espécie de padre. Em seus escritos, os normalistas reconheceram que, "como um bom pastor" (prova de José Salgado, 1875), o mestre devia cuidar de seus alunos, corrigir seus erros e dar-lhes exemplos. Ele se responsabilizava, assim, pelo ensino de conteúdos, mas, principalmente, pelo ensino da moral. Os exames da Escola Normal registraram afirmações muito sugestivas acerca da articulação entre as responsabilidades civis, morais e religiosas dos professores. Esses aspectos apresentavam-se nos textos dos normalistas como um amálgama. Segundo eles, ao professor também foi concedida a tarefa de oferecer à sociedade cidadãos valorosos que levariam a cabo o projeto de 
estruturação e progresso nacional. Magistério, vocação e cidadania apareciam como faces da mesma moeda. Um pequeno trecho da prova feita pelo normalista Cesário Adrien em 1875 permite notar esse tipo de afirmação:

O magistério primário é, de todas as ocupações do homem, a mais nobre e a mais santa depois do sacerdócio [...]. É a ocupação mais santa porque, livre das ambições mundanas, de interesses mesquinhos, só trata de dar à sociedade cidadãos virtuosos e ao Céu santos, completando assim a obra de Deus, como muito bem diz M. Daligault. (Prova de Cesário Adrien feita em 1875)

Em muitas provas encontramos as mesmas respostas ou, pelo menos, escritos com sentidos próximos. Ao transcrevê-las pode-se notar a configuração de um paradigma: as representações do professor como sacerdote e do magistério como vocação e salvação da sociedade tiveram uma força inegável nos escritos dos normalistas. Percebemos, pela mensagem presente em diversas provas, que o professor servia de instrumento de civilização e de progresso da nação. Os normalistas pareciam ter aprendido bem a lição do bom mestre. Convém retomar mais uma vez partes de provas encontradas. Numa delas, feita por Manoel dos Reys em 1875, o que se afirmava era a grande responsabilidade do professor. Se ele falhasse em sua missão, dizia o aluno, geraria

um gérmen de corrupção e de morte. [...] Pode-se, pois, afirmar: que o professor verdadeiramente digno desse nome dá à família filhos honrados e laboriosos; ao Estado cidadãos úteis e instruídos; à Igreja fiéis, e ao céu, santos. (Prova feita por Manoel dos Reys no ano de 1875)

Além da magnitude da docência, os alunos da Escola Normal destacavam uma espécie de modéstia que também marcava as representações do magistério. Os trechos acima transcritos evidenciavam o quanto os normalistas enfatizavam a atitude desinteressada que o professor deveria ter no exercício da profissão, tal como se fez presente nas prescrições de Daligault em seu manual pedagógico. Podemos resumir as representações das provas considerando que o magistério primário foi tido como uma santa ocupação por estar livre das ambições chamadas de mundanas e de interesses ditos mesquinhos.

Pelos excertos nota-se o propósito moralizante das aulas da Escola Normal e do discurso que se dirigiu aos seus alunos. Eles foram ensinados a valorizar um padrão de comportamento associado à religião, ao comedimento, à obediência e ao temor de Deus. Em prova realizada em 1875, Cesário Adrien escreveu que "o professor tem de corrigir os vícios de que seus alunos estiverem afetados e de inspirar-lhes o amor das virtudes sociais e ele não poderá cumprir este dever se não possuir esta virtude" (prova de Cesário Adrien, 1875). Os normalistas muitas vezes afirmaram um projeto civilizador baseado em regras de conduta social. Eles reconheceram de forma praticamente unânime que o exemplo seria dado pelo professor. Segundo o estudante José Ferreira, na prova que fez em 1875, o mestre é exemplo das relações que se devem ter na escola e com o Estado. Em suas palavras, o professor tem "deveres obrigatórios a cumprir; na sua correspondência com as autoridades, jamais deve usar de palavras ou escrito que não deixem ver senão decoro, submissão, respeito e acatamento" (prova de José Ferreira, 1875). 
Dentre tantas boas intenções e encantamentos para com a profissão, identificou-se um único trecho, numa única prova entre as 73 analisadas, que se dispôs a fazer uma reflexão sobre as qualidades que o professor deve possuir ${ }^{4}$, assinalando aspectos que não estavam postos no manual de Daligault. O normalista chegou a apontar alguma desvantagem no exercício da profissão docente. Com isso, o aluno contradizia o que pregava o manual, conforme se pode verificar no excerto a seguir:

É a ocupação mais ingrata porque o homem que a ela se dedica inteiramente vive como que isolado da sociedade, onde encontraria divertimentos, prazeres e gozos se outra fora sua ocupação; porque o homem que a ela se entrega, depois de passar uma vida cheia de privações, pois que faltam-lhes quase sempre recursos pecuniários, não vê sua velhice senão a continuação de tais privações e talvez mesmo a miséria. (Prova de Cesário Adrien, 1875)

Não se poderia deixar de transcrever o trecho acima, já que escapou à lógica de apropriação dos saberes pedagógicos nos exames da Escola Normal. Diferentemente das ressonâncias que confirmaram as representações do professor como sacerdote do Estado, as palavras de Cesário Adrien, ainda que de forma isolada, pontuaram questionamentos. Talvez outros normalistas concordassem com essas observações, embora não tivessem registrado isso nas provas. Pela citação acima se pode inferir sobre a condição dos profissionais da educação no período. A prova de Cesário Adrien deixou entrever que, apesar da insistente caracterização da profissão como algo a que se deve dedicar toda a vida e, por isso, privar-se de alguns convívios e eventos sociais, esses profissionais não tinham garantia de recursos que lhes permitiam uma vida digna. Talvez, por isso, a necessidade de se imprimir no espírito dos futuros professores, como uma das qualidades que deveriam possuir, o desinteresse.

Segundo José Salgado, outro normalista que fez prova em 1875, "o desinteresse consiste em o professor achar-se contente com o seu ordenado e buscar sua recompensa no progresso dos alunos e só deles cuidar" (prova de José Salgado, 1875). Podemos mais uma vez estabelecer aqui uma correspondência com o sacerdócio, uma vez que, em ambos os casos, esperava-se dedicação intensa e exclusiva pela nobreza da ação, cuja recompensa não devia ser esperada no plano material, mas, essencialmente, no plano espiritual.

Mais entre ressonâncias do que entre questionamentos, os exames da Escola Normal mostraram como as leituras foram direcionadas. Os saberes pedagógicos foram apropriados no sentido de produzir comportamentos ideais, para tornar os futuros professores cidadãos exemplares, obedientes ao Estado e aos princípios religiosos. Os normalistas mostraram ter aprendido bem essas lições. Em suas provas eles assinalaram sua missão, como cumpridores de seus deveres, comprometidos com o progresso da nação. E mais: subliminarmente assumiram em seus escritos o sucesso do projeto político governamental, não só da ação educacional especificamente escolar. Fazer um bom

\footnotetext{
${ }^{4}$ Como mencionamos, tais qualidades são apresentadas no manual pedagógico de mr. Daligault. As mesmas aparecem listadas nas provas intituladas $O$ professor e os seus predicados. Dentre as qualidades exigidas do futuro professor está o amor ao retiro, com a qual o excerto que apresentamos a seguir parecia dialogar diretamente, além de apontar as dificuldades que poderão ser vividas pelo professor devido aos baixos salários da categoria (Perez, 2012).
} 
exame significou assinalar essas ideias. Ter sucesso na Escola Normal e obter o diploma de professor primário foi investir nesses conhecimentos, exibidos nos exames. Isso foi exigido dos alunos e não é demais lembrar que esses foram os saberes exigidos dos alunos, para obtenção das notas. Essas foram apropriações específicas dos saberes pedagógicos, mas podemos nos interrogar sobre outras, que o questionamento do aluno Cesário Adrien (1875) mostrou serem possíveis, embora pouco ou quase nada registradas nas provas.

\section{Considerações finais}

Em nosso artigo, insistimos na ideia segundo a qual o espaço delimitado entre a leitura dos manuais pedagógicos e a escrita dos exames da Escola Normal foi um dos espaços possíveis para a apropriação dos saberes pedagógicos. Estamos tratando do início da formação de professores primários, quando os cursos começavam a se consolidar no país. Embora alguns títulos brasileiros e também portugueses já tivessem sido publicados na década de 1870, foi a tradução do Curso prático de pedagogia de Daligault (1874) a principal referência de estudo dos normalistas. Ele foi citado nas páginas dos outros manuais do período e também foi mencionado nas respostas feitas nas provas dos normalistas. Como todo manual pedagógico, o texto de Daligault tomou o ensino como seu objeto e, num momento em que a Pedagogia se consolidava como uma ciência da educação (Nóvoa, 1987), privilegiou as finalidades da escola, os métodos de ensino e o papel do professor. Esses temas foram sistematizados em textos acessíveis e claramente divididos, o que visava a facilitar sua compreensão e evitava dúvidas por parte de seus leitores.

Os manuais foram redigidos para pessoas que, via de regra, tinham concluído os quatro anos do primário e se preparavam para o magistério nas escolas normais ou estudavam para os concursos de ingresso na carreira. Os livros não se apresentavam como originais, pelo contrário, seu intuito era reunir as principais ideias de literatura educacional, intermediando a leitura que os professores faziam dos grandes autores da área. Notamos, a partir do exame do conteúdo dos manuais da época, que seus textos direcionavam as interpretações para uma espécie de receituário de como ensinar e buscavam produzir, assim, uma cultura pedagógica. Esses livros foram o primeiro, e talvez o único, contato que professores primários tiveram com os saberes pedagógicos.

Enquanto leitores dos manuais, os normalistas mobilizaram nos exames do curso estratégias de sobrevivência (Perrenoud, 1995) que já conheciam desde seus tempos nos bancos da escola primária. Nas provas, eles parafraseavam e até mesmo reproduziam trechos das referências encontradas no livro de Daligault (1874). Eram muito hábeis, portanto, na memorização do que tinha sido exposto ao longo do Curso Normal. As notas satisfatórias tiradas com essa estratégia mostraram que era isso o que os professores esperavam de seus alunos: "De ano para ano, o aluno aprende a ser avaliado, apanha em que é que geralmente o professor fundamenta a sua apreciação" (Perrenoud, 1995, p. 138). A grande recorrência de transcrição ou paráfrases do texto de Daligault (1874) ou de conceitos presentes em praticamente todas as provas nos conduz a pensar que esta foi a competência acordada, implícita ou explicitamente, entre os professores e os alunos da Escola Normal. 
Ler, nessa perspectiva, significou memorizar as ideias fundamentais do que se queria para a escola, para o ensino e para o magistério. Essa espécie de leitura escolarizada aproximou-se das práticas que tradicionalmente caracterizaram a escola primária, bem como os manuais e as provas cercaram uma modalidade de apropriação dos saberes pedagógicos notável entre os normalistas. Trata-se, como vimos, de uma prática permitida no curso, que reservou mais espaço para as reproduções e memorizações e, assim, contribuiu para tornar os conhecimentos dos manuais como as únicas alternativas possíveis para se pensar a educação, a escola e o magistério.

\section{Referências}

BASTOS, Maria Helena Câmara. Aprendendo o labor docente: o curso prático de pedagogia de Jean-Baptiste Daligault (1851). COLOQUIO NACIONAL DE HISTORIA DE LA EDUCACION: ARTE Y OFICIO DE ENSEÑAR. DOS SIGLOS DE PERSPECTIVA HISTÓRICA, 16, 2011, Valladolid. Anales ... Valladolid: Sedhe/Ceince/Universidad de Valladolid, 2011, p. 497-505.

BERNSTEIN, Basil. On pedagogic discourse. In: RICHARDSON, John. (ed.). Handbook of theory and research for the sociology of education. New York, Westport Conn., and London: Greenwood Press, 1986, p. 205-240.

BOTO, Carlota. Ler, escrever, contar e se comportar: a escola primária como rito do século 19 português. São Paulo: FFLCH, 1997. 650f. Tese (doutorado em Educação). Faculdade de Letras, Filosofia e Ciências Humanas, Universidade de São Paulo.

BOURDIEU, Pierre. As regras da arte. São Paulo: Cia. das Letras, 1996.

CATANI, Denice Barbara. Ensaios sobre a produção e circulação dos saberes pedagógicos. São Paulo: USP, 1994. 167f. Tese (livre docência). Faculdade de Educação, Universidade de São Paulo.

CHARTIER, Roger. A ordem dos livros: leitores, autores e bibliotecas na Europa entre os séculos XIV e XVIII. Brasília: UnB, 1998.

CHERVEL, André. História das disciplinas escolares: reflexões sobre um campo de pesquisa. Teoria e Educação. Porto Alegre, Pannônica, n. 2, 1990, p. 177-229.

DEPAEPE, Marc. Order in progress: everyday education practice in primary schools Belgium, 1880-1970. Bélgica: Leuven University Press, 2000.

DEPAEPE, Marc. The practical and professional relevance of educational research and pedagogical knowledge from the perspective of history: reflections on the Belgian case in its international background. European Educational Research Journal, v. 1, n. 2, 2002, p. 360-379.

FERNÁNDEZ, Narciso de Gabriel; SALVADO, José Luis Iglesias. Los libros y guías para el maestro. In: BENITO, Agustín Escolano (dir.). Historia ilustrada del libro escolar en España de la posguerra a la reforma educativa. Madrid: Fundación Germán Sánchez Ruipérez, 1998, p. 439-468.

JULIA, Dominique. La culture scolaire comme objet historique. Paedagogica Histórica, v. 1, 1995, p. 353-382.

ESCOLANO BENITO, Agustín. The historical codification of the manualistics in Spain. Paedagogica historica, Universitaire Stichting van België, XXXVIII, 1, 2002, p. 51-72. 
ESCOLANO BENITO, Agustín. Arte y oficio de enseñar. In: PERANDONES, Pablo Celada. COLOQUIO NACIONAL DE HISTORIA DE LA EDUCACION: ARTE Y OFICIO DE ENSEÑAR. DOS SIGLOS DE PERSPECTIVA HISTÓRICA, 16, 2011, Valladolid. Anales ... Valladolid: Sedhe/Ceince/Universidad de Valladolid, 2011, p. 17-26.

FOUCAULT, Michel. Vigiar e punir: história da violência nas prisões. Petrópolis: Vozes, 1987.

GALLEGO, Rita de Cássia. Tempo, temporalidades e ritmos nas escolas públicas primárias em São Paulo (1846-1890) - heranças e negociações. São Paulo: USP, 2008. 328f. Tese (doutorado em Educação). Faculdade de Educação, Universidade de São Paulo.

GONDRA, José. Medicina, higiene e educação escolar. In: LOPES, Eliane Marta Teixeira; FARIA FILHO, Luciano Mendes de; VEIGA, Cynthia Greive (orgs.). 500 anos de educação no Brasil. Belo Horizonte: Autêntica, 2000, p. 519-550.

LOURENÇO FILHO, Manoel Bergstrom. Tendências de educação brasileira. São Paulo: Melhoramentos, 1941.

MONARCHA, Carlos. Escola Normal da Praça: o lado noturno das luzes. Campinas: Unicamp, 1999.

NÓVOA, António. Le temps des professeurs. Lisboa: Inic, 1987.

NÓVOA, António; SCHRIEWER, Jürgen (eds.). A difusão mundial da escola. Lisboa: Educa, 2000.

PEREZ, Tatiane Tanaka. História da formação de professores em São Paulo (1875-1894): intersecções entre os ideais de professor e de escola. São Paulo: USP, 2012. 333f. Dissertação (mestrado em Educação). Faculdade de Educação, Universidade de São Paulo.

PERRENOUD, Philippe. Ofício de aluno e sentido do trabalho escolar. Porto: Porto, 1995.

PERRENOUD, Philippe. Avaliação: da excelência à regulação das aprendizagens, entre duas lógicas. Porto Alegre: Artmed, 2008.

SILVA, Vivian Batista da. História de leituras para professores: um estudo da produção e circulação de saberes especializados no manuais pedagógicos brasileiros (19301971).São Paulo: USP, 2001. 244f. Dissertação (mestrado em Educação). Faculdade de Educação, Universidade de São Paulo.

SILVA, Vivian Batista da. Saberes em viagem nos manuais pedagógicos: construções da escola em Portugal e no Brasil (1870-1970). São Paulo: USP, 2005. 400f. Tese (doutorado em Educação). Faculdade de Educação, Universidade de São Paulo.

ROGAN, John M.; LUCKOWSKI, Jean A. Curriculum texts: the portrayal of the field. Part 1. Journal Curriculum Studies, v. 22, n. 1, 1990, p. 17-39.

ROULLET, Michèle. Les manueles de pédagogie (1880-1920): apprendre à enseigner dans les livres? Paris: Presses Universitaires de France, 2001.

ROULLET, Michèle. Manuels de pédagogie et de psychologie dês écoles normales en France entre 1880 et 1920. These de Docteur. Genève: Université de Genève, 1998.

SCHNEIDER, Michel. Ladrões de palavras: ensaio sobre o plágio, a psicanálise e o pensamento. Campinas: Unicamp, 1990. 
PINTADO, Antonio Molero. Los manuales de historia de la educación y la formación de los maestros (1900-1930). Historia de la educación - Revista Interuniversitaria. Universidad de Salamanca, n. 19, 2000, p. 121-139.

TANURI, Leonor. História da formação de professores. Revista Brasileira de Educação, n. 14, 2000, p. 61-88.

TANURI, Leonor. O ensino normal no Estado de São Paulo: 1890-1930. São Paulo: USP, 1979, 234f. Tese (doutorado em Educação). Faculdade de Educação, Universidade de São Paulo.

TREVISAN, Thabatha Aline. História da disciplina pedagogia nas escolas normais do estado de São Paulo (1874-1959). Marília: Unesp, 2011. 222f. Tese (doutorado em Educação). Faculdade de Educação, Universidade Estadual Paulista.

VILLELA, Heloisa de Oliveira S. A primeira escola normal do Brasil: uma contribuição à história da formação de professores. Niterói: UFF, 1990. Dissertação (mestrado em Educação). Universidade Federal Fluminense.

VILLELA, Heloisa de Oliveira S. Da palmatória à lanterna mágica: a Escola Normal da Província do Rio de Janeiro entre artesanato e a formação profissional (1868-1876). São Paulo: USP, 2002. 291f. Tese (doutorado em Educação). Faculdade de Educação, Universidade de São Paulo.

VIVIAN BATISTA DA SILVA é professora na Faculdade de Educação da Universidade de São Paulo, doutora em Educação pela mesma instituição.

Endereço: Rua Adalberto Kurt, 665 - 05138-040 - São Paulo - SP - Brasil.

E-mail: vivianbs@yahoo.com.

TATIANE TANAKA PEREZ É doutoranda em Educação pela Faculdade de Educação da Universidade de São Paulo, mestre em Educação pela mesma instituição.

Endereço: Rua Fidalga, 627 - 05432-070 - São Paulo - SP - Brasil.

E-mail: tati tanaka@hotmail.com.

Recebido em 9 de julho de 2013.

Aceito em 14 de outubro de 2013. 